\title{
Random placement and the distribution of fishes among coral patch reefs
}

\author{
P. F. Sale \& W. J. Steel \\ School of Biological Sciences, University of Sydney, Sydney 2006, N. S. W., Australia
}

\begin{abstract}
On the basis of repeated censuses of unmanipulated assemblages of fish on 20 lagoonal patch reefs, Sale \& Douglas (1984) proposed a simple random placement model to account for the structure of such reef fish assemblages. The present paper uses their data augmented by additional censuses and a series of simulation models to explore the adequacy of their proposal. The distributions of a small proportion (about 8 species) of the 143 species recorded on the reefs, but including some of the most abundant species, could not be explained by a process of random colonization. These species vary greatly in abundance among censuses, and tend consistently to prefer certain reefs. The remaining species, while clearly possessing some microhabitat requirements, and perhaps responding to each other's presence, show distribution across patch reefs which are satisfactorily explained by a model of random placement of juveniles from a pool of potential colonists.
\end{abstract}

\section{INTRODUCTION}

The question of the extent to which biotic communities are strongly structured by interactions among their component species is currently receiving substantial attention by ecologists. Are the diversity and/ or the relative or absolute abundance of species in a local assemblage determined by biotic interactions such as competition and predation among resident individuals, or by factors extrinsic to the assemblage such as weather, habitat characteristics, or other factors influencing abilities to disperse and to survive? There is a diversity of views on this question. For entry to this literature see Cody \& Diamond (1975) and Strong et al. (1984).

In recent years, this general question has been explored in several different ways using assemblages of coral reef fishes. This system has some advantages. Assemblages of fishes are resident on small patches of suitable habitat such as patch reefs of only a few square metres in surface area. These assemblages are usually rich in species but amenable to visual census so that their structure can be monitored non-destructively, and followed through time. Its important to note, however, that these assemblages are fundamentally different in their mode of formation and persistence to those of many other habitats which have been studied. Because all but 2 or 3 species of reef fish world-wide export all their eggs or larvae to the plankton of the open water (Thresher 1984), all recruitment to these assemblages is by means of immigration of settling larvae which metamorphose into new juvenile members of the assemblage. The growth in numbers of a species present at a site is due solely to successive settlements of new juveniles, and is independent of the reproductive success of resident individuals (Sale 1977, 1980).

One might anticipate that interspecific interactions within these assemblages would strongly influence their structure. They are built up through successive arrivals of small juveniles perhaps ill-equipped to face the negative competitive or predatory interest of prior residents. There occur abundant instances of easily observable aggression both within and among species in such assemblages. There has also been the assumption that space, if not also other resources, is often in short supply (Sale 1980). In fact, studies exploring the structure of assemblages have yielded mixed results.

Many workers who have sampled assemblages at one time have detected patterns in the structure of assemblages they sampled (Smith \& Tyler 1972, Anderson et al. 1981, Gladfelter et al. 1980). Patterns of species composition have been related to the nature of the habitat occupied, and competitive interactions among species sometimes have been invoked as causal agents of these. Some studies which have monitored 
assemblages on natural or artificial habitats over periods of time have found that the structure of assemblages was rather constant (Smith \& Tyler 1975 , Brock et al. 1979. Ogden \& Ebersole 1981), further supporting the notion of intrinsic regulation of structure. However, most recent studies have found a substantial degree of temporal change in structure of assemblages (Sale 1979, Sale \& Dybdahl 1975, 1978, Talbot et al. 1978, Bohnsack \& Talbot 1980). This change has not been closely related to any changes in the structure of the habitat, nor to any patterns of interaction among component species. It must be admitted, however, that the role of interspecific interaction in determining assemblage structure has not been critically examined until very recently (see 'Discussion')

Sale \& Douglas (1984) recently reported on a continuing study in which assemblages on 20 undisturbed patch reefs have been repeatedly censused since 1977 Their paper used the first 8 censuses of these reefs spanning $3.5 \mathrm{yr}$. Reefs varied in size from 2.34 to $28.35 \mathrm{~m}^{2}$ surface area, and were located in 2 groups of 10 on the north-east and on the south side of the lagoon of One Tree Reef. All were similar in structure and in a similar depth of water on a sandy lagoon floor. A total of 143 species was recorded in the 8 censuses, and while single reefs supported an average of 21 species and 128 individuals at any one census, change in assemblage structure was substantial. Over the 8 censuses, the average reef was occupied by 46 species of fish.

The results of Sale \& Douglas (1984) can be summarized by the following 3 points: (1) the structure of assemblages was not strongly related to any attribute of the reefs other than size (larger ones supported bigger assemblages with more species); (2) the distributions of component species were largely independent of measured attributes of the reefs $;$ and (3) temporal change in structure was predominantly aseasonal, and unpredictable in direction.

Sale \& Douglas (1984) proposed a simple, noninteractive model of assemblage formation and maintenance to account for these results, although they admitted that this model was too simple to be a sufficient explanation of the details in their data. The model assumes that all fish present in an assemblage at any time are the result of independent immigration and subsequent survival of individuals. It also assumes the the rates of immigration and persistence are characteristics of each species which are not influenced by the composition of fish already present in any particular assemblage. Finally, it assumes that any of the 143 species of fish can successfully settle and persist on any of the 20 reefs, although some reefs, chiefly because of their larger size but perhaps also because of other attributes of structure or location, will normally support more individuals than others. In this model, the size and structure of the assemblage present on a particular reef at a particular time are functions of recent past history at that site, in that they are a simple consequence of which species, and in what numbers, have happened randomly to settle and survive at that site.

The model proposed by Sale \& Douglas (1984) is in effect a type of random placement model (see Simberloff 1978, McGuinness 1984). For our purposes it represents an hypothesis which could account for the observed species distributions on patch reefs. We believe that it is not necessary to invoke more 'sophisticated' hypotheses as explanations for these distributions unless the more simple hypothesis proves inadequate. In this paper we examine the model of Sale \& Douglas (1984) and a set of closely related simulation models, using their data extended by 2 additional censuses. We determine the extent to which this simple model must be modified to account adequately for observed patterns in the assemblages.

\section{METHODS}

The field work was done at One Tree Reef $\left(23^{\circ} 31^{\prime} \mathrm{S}\right.$, $152^{\circ} 06^{\prime} E$ ), southern Great Barrier Reef, from August 1977 to November 1981. The assemblage of fish present on each of 20 small lagoonal patch reefs was censused on each of 10 occasions during this time. Descriptions of the study site, the patch reefs used, and the visual census technique employed are in Sale \& Douglas (1984). The precision of this census method is examined in Sale \& Douglas (1981). The 20 patch reefs were undisturbed throughout this time, apart from visits necessary to census fish.

The matrix of census data (number of individuals of species, on reefs, at censuses) provides the raw material for the present paper. Aspects of the structure of assemblages found on the reefs are compared with those of pseudoassemblages generated by a series of null models.

We commenced with the assumption that the particular mix of species present on a reef at a census could be thought of as a consequence of the settlement and subsequent survival on that reef of a series of individuals drawn, in some fashion, from a pool of species able to live there. Rather than attempt to model rates of settlement, and of subsequent mortality separately, we use the term 'successful recruitment' for the amalgam of these 2 processes. The rate of successful recruitment of a species is a measure of its chance of having an individual present on the reef at the census.

The primary hypothesis examined is that the rate of 
successful recruitment of a species is a function of the relative abundance of that species in the pool, and is not dependent on the species composition of the assemblage being joined. That rates of successful recruitment may vary among species or among reefs is not incompatible either with acceptance or rejection of this hypothesis. Such variation among reefs and species is accepted as real, and is not tested. Our general procedure was to build up, by means of random recruitment from a general species pool, pseudoassemblages of the same size as assemblages on actual reefs. The species pools were all ones in which substantial differences in abundance, and therefore in chance of recruitment, existed among the species. They were formed by 5 different models, all using data available in the matrix of census results.

Model 1. This least restrictive null model is that of Sale \& Douglas (1984). It assumes that the best estimate of the composition of the species pool which generates assemblages present at a census is the set of species abundances summed over all 20 reefs at that census. Probability of successful recruitment by a species is equal to the relative abundance of that species in the pool. This probability is constant across reefs at that census time. Composition of the pool, and hence rates of successful recruitment, vary among censuses.

Model 2. This model recognizes that Model 1 may not be appropriate for all species. In particular, those species that show large fluctuations in numbers across reefs or censuses, or both, will tend to swamp the analysis. For each species the mean abundance and associated variance were calculated over all reefs and censuses. We explored the consequences of excluding the most variable species, and eventually chose a variance-to-mean ratio of 12.0 as the cut-off point. Eight species had ratios greater than this and were excluded. For each census, the composition of the species pool of included species was determined as for Model 1.

Model 3. For this model, it is assumed that not all species may be capable of successfully accupying a particular reef. Those species present at a particular reef for at least 1 of the 10 censuses are considered the pool from which recruitment to that reef occurs. Their relative abundance in the pool at a given census is determined from their abundances summed over all 20 reefs at that census. For this model, relative rates of successful recruitment vary among reefs and among censuses, and different sets of species are examined for each reef.

Model 4. This model removes from consideration those 8 species excluded by Model 2 because of their pronounced fluctuations in abundance, then determines species pools for each reef as in Model 3.

Model 5 . In this model, procedures followed to deter- mine the composition of the species pool were those used in Model 1. However, in recognition of the fact that the northeast group of 10 reefs had previously been shown to have some general faunistic differences to the south group (Sale \& Douglas 1984), the 2 groups of reefs were treated separately. Thus, for any northeastern reef, for example, the species pool was estimated from the summed abundances of species on the 10 northeastern reefs at the specified census.

Having determined the relative rates of successful recruitment by one of these models, we permitted random recruitment using these rates, until a number of fish equal to the number present on a specified reef was reached. This process was repeated until 10 pseudoassemblages of this size were obtained. In cases where Models 2 or 4 were used to specify the pool, the number of fish added to form the assemblages was the number present on the reef after excluded species were deleted. The process of generating pseudoassemblages was repeated for each reef in turn.

As a consequence of the results of some of our initial 5 models, a further model (Model 6) was developed to investigate the following. The possibility exists, even for species which tend to occur in small numbers on patch reefs, that chance of settlement is influenced by whether or not conspecifics are present (Sweatman 1983). Model 6 crudely mimics such a varying probability of recruitment.

Model 6. The composition of the species pool is determined as in Model 1. The process of random recruitment of individuals is amended so that each species, on its first occasion of being added to a pseudoassemblage, has 2 individuals added instead of 1. Thus the pseudoassemblages never contain single representatives of any species, although subsequent recruitment of that species is the same as in Model 1.

Analyses compared actual assemblages on each reef at each census to equivalent pseudoassemblages in 2 ways. In both cases, significant differences were detected simply by reference to $95 \%$ confidence limits computed around means. This simple approach was adopted because all such limits were very narrow, and results were usually very clear. The number of species present in each assemblage was compared to the mean number present in the respective pseudoassemblages. The mean similarity of composition of each assemblage to its set of 10 pseudoassemblages was compared to that among all pairs of the 10 pseudoassemblages. These comparisons used the proportional similarity index.

$$
\mathrm{C}_{\mathrm{ij}}=1-0.5 \sum_{\mathrm{n}=1}^{\mathrm{s}}\left|\mathrm{p}_{\mathrm{ih}}{ }^{--} \mathrm{p}_{\mathrm{jh}}\right|
$$

where $C_{1]}=$ the proportional similarity between assemblages $\mathrm{i}$ and $j_{;} \mathrm{p}_{\mathrm{ih}}$ and $\mathrm{p}_{\mathrm{jh}}=$ respectively, the proportion of fish in assemblages $i$ and $j$ which belong 
to species h. Since similarity values were nearly always within the range 0.3 to 0.7 , no transformation was applied to sets of values before computing confidence limits.

\section{RESULTS}

Model 1, the least restrictive procedure, generated pseudoassemblages which differed consistently from the assemblages they were intended to mimic. The pseudoassemblages usually contained significantly more species and were almost always (98\% of cases) significantly more similar to one another than they were to the natural assemblages with which they were compared (Table 1). Averaged over all reefs and censuses, the similarity among pseudoassemblages was $0.701 \pm 0.003 \mathrm{SE}$, and that between pseudoassemblages and natural assemblages was $0.473 \pm 0.003 \mathrm{SE}$. Pseudoassemblages averaged $27.07 \pm 0.21 \mathrm{SE}$ species, about 6 more than the mean number of $20.81 \pm 0.53 \mathrm{SE}$ present on the natural assemblages. Model 1 did succeed in generating sets of pseudoassemblages which tracked the major variations in number of species which existed among reefs and censuses (Fig. 1).

Model 2 eliminated from consideration 8 species

Table 1. Comparisons (a) between number of species in pseudoassemblages and in natural assemblage, (b) between similarity of pseudo- and natural assemblage and similarity among pseudoassemblages, generated by Models 1 to 4 , Model 6, and by a noncircular variation of Model 1 (see 'Discussion'). Comparisons are based on $95 \%$ confidence limits, are not adjusted to correct for effects of multiple tests.

Twenty reefs $\times 10$ censuses $=200$ comparsions made

(a) No. of species in pseudoassemblages significantly:

\begin{tabular}{|c|c|c|c|}
\hline & less & not different & more \\
\hline Model 1 & 10 & 44 & 146 \\
\hline Model 2 & 13 & 36 & 151 \\
\hline Model 3 & 63 & 69 & 68 \\
\hline Model 4 & 58 & 70 & 72 \\
\hline Model 6 & 49 & 41 & 110 \\
\hline $\begin{array}{l}\text { Model } 1 \\
\text { (noncircular) }\end{array}$ & 11 & 40 & 149 \\
\hline \multicolumn{4}{|c|}{$\begin{array}{l}\text { (b) Similarity of pseudo- to natural assemblage } \\
\text { significantly: }\end{array}$} \\
\hline & less & not different & more \\
\hline Model 1 & 196 & 4 & 0 \\
\hline Model 2 & 117 & 83 & 0 \\
\hline Model 3 & 195 & 5 & 0 \\
\hline Model 4 & 119 & 81 & 0 \\
\hline Model 6 & 192 & 8 & 0 \\
\hline $\begin{array}{l}\text { Model } 1 \\
\text { (noncircular) }\end{array}$ & 197 & 3 & 0 \\
\hline
\end{tabular}

whose numbers varied widely across both reefs and censuses, and about $50 \%$ of individuals present on reefs. This model generated pseudoassemblages with slightly higher similarity (about $10 \%$ ) to the natural assemblages than those generated by Model 1 . The mean similarity between pseudoassemblages and natural assemblages was $0.524 \pm 0.006 \mathrm{SE}$, and that amongst the pseudoassemblages was $0.619 \pm 0.004$ SE. More importantly, there were fewer occassions in which sets of pseudoassemblagaes were significantly more similar to one another than they were to the natural assemblages (Table 1). Mean species richness of pseudoassemblages was $21.90 \pm 0.17 \mathrm{SE}$, about 5 more species than the mean of $17.02 \pm 0.46 \mathrm{SE}$, for natural assemblages.

Instances in which pseudoassemblages and natural assemblages did remain relatively dissimilar occurred on 5 of the 20 reefs (Reefs 1,2,16,18\& 19: Fig. 2). This is despite the fact that 4 of these same reefs (Reefs $1,16,18$ \& 19) showed improvement in simulated number of species under Model 2. In $50 \%$ of cases the number of species in pseudoassemblages on these reefs was not significantly different $(p<0.05)$ to number in the natural assemblages, and in $30 \%$ of cases the number of species in the pseudoassemblages was significantly less than the number in the natural assemblages. This is a reversal of the general trend for the remaining 16 Reefs, in which these figures were 8.5 and $0 \%$, respectively. So despite improvement in number of species for Reefs 1, 16, 18 and 19 under Model 2, there is something causing natural assemblages to remain dissimilar to pseudoassemblages on these reefs. Inspection of assemblages formed on each of these reefs identified species which differed markedly in abundance at 1 or more censuses from their mean abundance over all reefs and censuses. They were all species with variance/ mean ratios among the 10 highest after the 8 excluded by Model 2. It is probable that further improvement in similarity between pseudo- and natural assemblages would be obtained by deleting this small group of additional species from consideration.

Model 3 considered only those species which used a given reef at least once during the 10 censuses. This model generated pseudoassemblages with numbers of species that were very close to those of the natural assemblages. Mean species richness of pseudoassemblages (20.35 $\pm 0.10 \mathrm{SE})$ was not significantly different to that of natural assemblages $(20.81 \pm 0.53 \mathrm{SE})$. The pseudoassemblages were also more similar to the natural assemblages than those generated by Model 1. Mean similarity of pseudo- to natural assemblages was $0.530 \pm 0.004$ SE (compared with $0.473 \pm 0.003 \mathrm{SE}$ under Model 1). Replicate pseudoassemblages, however, were usually more similar to one another than to the mimicked natural assemblages (Table 1). 
Fig. 1. Natural assemblages and pseudoassemblages generated by Model 1 for 3 representative reefs (Reefs $6,10, \& 18$ ). (A) Average similarity of fauna amongst pseudoassemblages $(\bullet)$. and between pseudo- and natural assemblages (A). (B) Average number of species in pseudoassemblages ( $\bullet$ ) compared with number in natural assemblages ( $\downarrow$ ). All error bars represent $95 \%$ confidence limits
Fig. 2. Natural assemblages and pseudoassemblages produced by Model 2 for the same 3 reefs as in Fig. 1. (A) \& (B) as in Fig. 1. Reefs 6 and 10 are typical of the 15 reefs which showed improvement under Model 2. Reef 18 is an example of a reef which showed no improvement (see text for details)
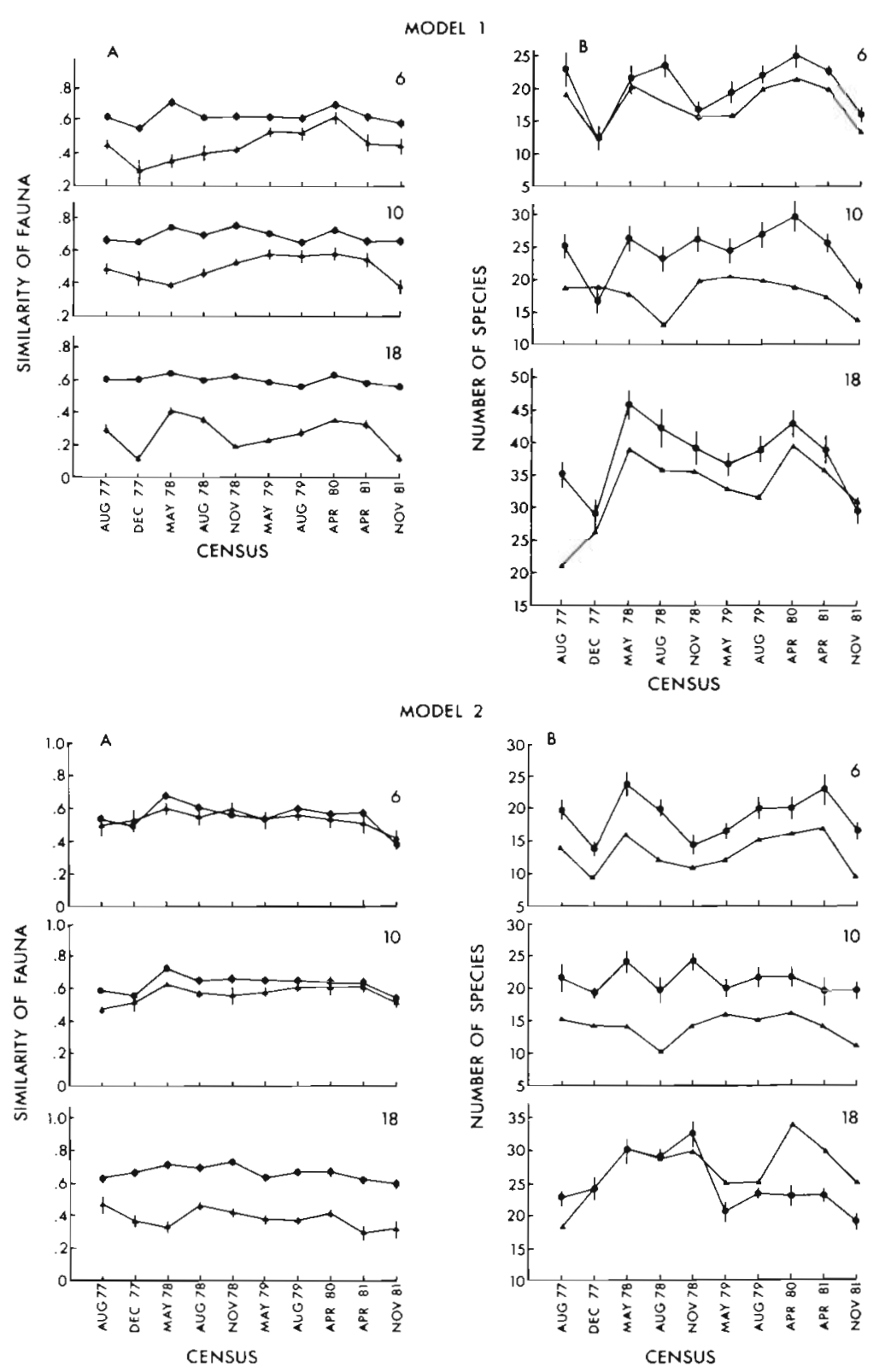

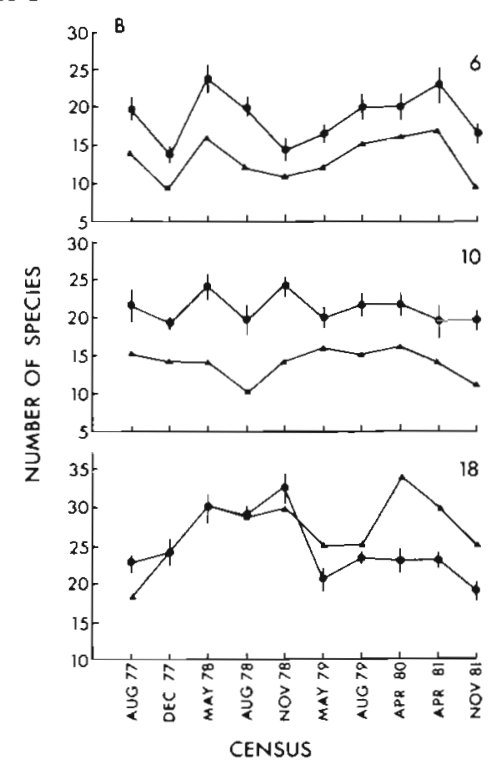

Model 4, which combined procedures of Models 2 and 3 , yielded pseudoassemblages which reflected the desirable properties of both these models. Thus, as for Model 3, numbers of species closely followed those in natural assemblages, and as in Model 2, there were many more instances in which the faunal similarity between pseudo- and natural assemblages were close (Fig. 3). Once again, instances in which pseudoassemblages and natural assemblages did remain dissimilar occurred on only 5 reefs $(1,2,16,18 \& 19)$. Mean similarity between pseudo- and natural assemblages was $0.589 \pm 0.004 \mathrm{SE}$, a slight improvement over that obtained using Models 2 or 3.

Model 5 treated assemblages on the northeastern (Reefs 1 to 10 ) and the southern reefs (Reefs 11 to 20) separately, but otherwise acted as Model 1. It was run for 2 of the 10 censuses, and showed no substantial improvement over Model 1 in either similarity or number of species in pseudoassemblages.

Model 6, which did not allow individuals of a species to occur singly, did not result in pseudoassemblages that were more similar to the natural ones than did Model 1 (Table 1). In the great majority of sets, pseudoassemblages were significantly more similar to one another $(0.65 \pm 0.003 \mathrm{SE})$ than they were to the natural assemblage $(0.453 \pm 0.003 \mathrm{SE})$. In about $25 \%$ of cases the pseudoassemblages contained significantly fewer species than the natural assemblages they were intended to mimic. 


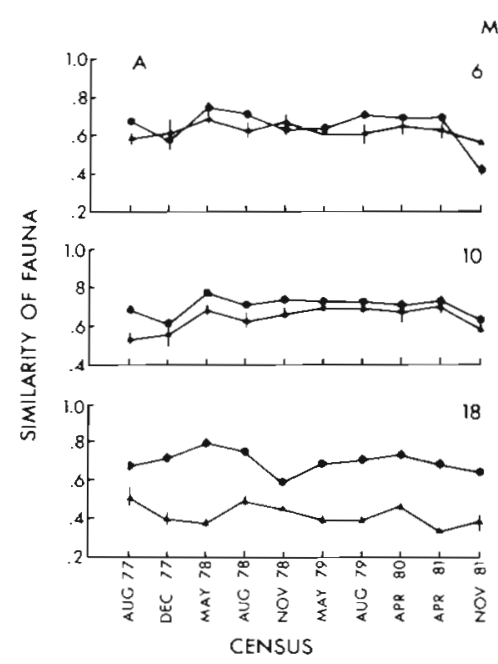

MODEL 4

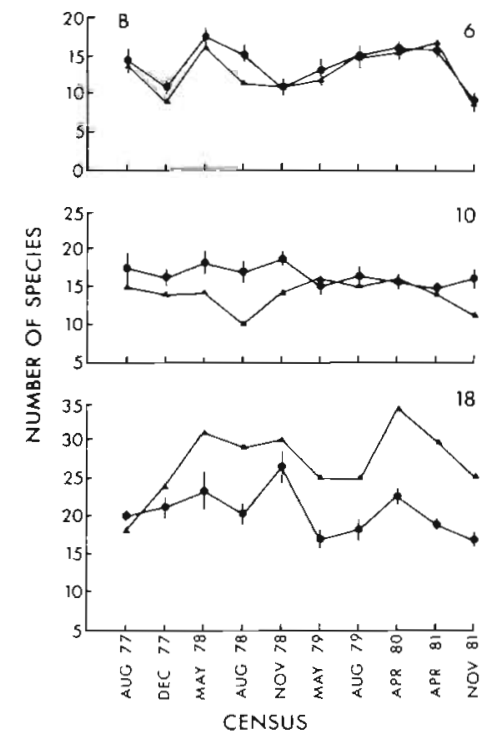

Fig. 3. Natural assemblagaes and pseudoassemblages produced by Model 4 for the same 3 reefs as in Fig. $1 \& 2$. (A) \& (B) as in Fig 1 \& 2

\section{DISCUSSION}

\section{Assumptions}

Our purpose in simulating assemblages has been to assess the degree to which noninteractive colonization of reefs by individual fish is an adequate model of assemblage formation. Before considering the results of our study we must justify certain of the assumptions underlying the models used.

Our major assumption is that the relative abundance of species present on the patch reefs can be used as an index of their relative colonising abilities. Of the 143 species recorded on the 20 patch reefs, only Acanthochromis polyacanthus is known to lack a pelagic larval phase. Mated pairs of this pomacentrid defend a clutch of young for up to $30 \mathrm{~d}$ by which time the young are able to support themselves in the patch reef environment (Robertson 1973, Thresher 1983). Young A. polyacanthus disperse among patch reefs, travelling in small groups (Thresher 1983). Apart from this exception, fish arrive on patch reefs by settling from the plankton.

Species vary in the rates at which they settle and in the pattern of mortality following settlement. Data on early post-settlement mortality (Doherty \& Sale 1985 , Sale unpubl.) indicate a wide range, from species which settle in small numbers and then show high survivorship (perhaps $50 \%$ of settlers reaching maturity), to species, particularly of the Scaridae and Apogonidae, which settle in large numbers to form dense aggregations, most members of which die in the first few weeks following settlement. In at least some of these latter species, simultaneous settlement of small groups of larvae may take place, and settling fish certainly join already established aggregations.

It is clear that with these different patterns of settlement and subsequent survivorship, the relative abundances of species resident on the reefs do not provide evidence directly of relative rates of settlement. However, they should be consistent with relative abilities to settle and subsequently survive. We use the term 'successful recruitment' to denote this process of settling and surviving, and since the models are all intended to be noninteractive ones, we assume that rates of successful recruitment are not influenced by the presence or absence of other resident fishes.

A second assumption is that the small degree of circularity built into the models neither biases nor trivialises the results. Each of the 6 models uses data drawn from all 20 reefs to develop a set of relative abilities to successfully recruit. This set of abilities is then used to generate, for each reef in turn, sets of pseudoassemblages of the same size as the assemblage present on it. Clearly, the assemblage present on a reef has contributed to the development of the set of relative abilities to successfully recruit, and these are used to generate the pseudoassemblages for comparison. The extent of this circularity is slight. The largest reef accounts for about $14 \%$ of individuals present at the average census, and the average reef for only $5 \%$ of individuals. We examined the effect of this circularity by modifying Model 1 such that the fauna present on a natural reef was excluded from the species pool used to generate pseudoassemblages for that reef. Similarity values were found to differ only marginally, and the qualitative results were unchanged (Table 1). Mean similarity among pseudoassemblages was 
$0.702 \pm 0.007 \mathrm{SE}$, and mean similarity of these to natural assemblages was $0.448 \pm 0.007 \mathrm{SE}$ using this noncircular technique. In view of the extra cost of running these simulations, we chose to ignore the minor circularity of the more straightforward procedures.

\section{Comparison of the models}

Our results for Model 1 show that a completely random pattern of successful recruitment of individuals does not produce assemblages closely ressembling those observed on the patch reefs. Pseudoassemblages generated by this model support a greater number of species, and they show little faunal similarity to natural assemblages they were intended to mimic. Models 2 and 3 each correct one of these failures to mimic reality

Model 2, by setting aside 8 species from consideration, generated a set of pseudoassemblages which were more similar to the natural assemblages than those produced by Model 1. The mean similarity of $0.524 \pm 0.006$ SE between pseudo- and natural assemblages still indicates some substantial differences among them. However, this is the same degree of variation which Sale \& Douglas (1984) recorded among successive assemblages on these patch reefs, and which occurs among the pseudoassemblages themselves $(0.618 \pm 0.004 \mathrm{SE})$. If assemblages are generated stochastically, faunistic differences will occur among replicates unless the sizes of the assemblages are large relative to the size of the pool of recruits. The important result is not that similarities are not close to 1.0 , but that the similarity of the natural assemblages to the pseudoassemblages is close to, and less often significantly different from, the similarity among replicate pseudoassemblages (Table 1, Fig. 2).

The 8 species excluded by Model 2 were those that had the highest variation in numbers of individuals across all reefs and censuses. These 8 species included Acanthochromis polyacanthus and 3 more typical pomacentrids (Chromis nitida, Dascyllus aruanus, and Pomacentrus molluccensis $=P$. popeil, 1 goby (Gobiodon okinawe), and 3 apogonids (Apogon doederleini, A. gracilis, and Cheilodipterus quinquelineata). Of these, D. aruanus, $P$. molluccensis, and $G$. okinawe are microhabitat specialists requiring living branched coral (Sale et al. 1984, unpubl.). The remaining 5 species are ones which occur in dense aggregations as juveniles and may settle onto reefs in small groups rather than as individuals. D. aruanus also shows a tendency to recruit to groups of conspecifics (Sweatman 1983). As earlier mentioned it is probable that further exclusion of just a few more of the next most highly variant species would result in an even better fit of Model 2.

What are the characteristics of these 8 species which lead to better simulations when these species are removed from consideration? They are abundant species which, although representing only $5.5 \%$ of the species pool, account for $53 \%$ of individuals recorded in censuses. One of them, Apogon doederlini, accounts for about $25 \%$ of all sightings. The high coefficient of variation these species possess might be due to pronounced variation in abundance across censuses, across reefs, or both. We examined the matrix of abundances on reefs at censuses for each species, and observed in most cases that while there were marked variations among both reefs and censuses, certain reefs did seem to be consistently occupied while the species was rare or absent on others. We examined this apparent consistency of use of reefs by each species by using data on abundance on each reef to rank the 20 reefs at each census. We then used Kendall's coefficient of concordance to test whether the rankings of reefs were significantly similar across the 10 censuses.

Six of the 8 species exhibited highly significant concordance $(\mathrm{P}<0.001)$ indicating that their relative abundance among reefs tended to be consistent from one census to another (Table 2). The numbers of the other 2 species were such that a test by this analysis would have been trivial. Apogon gracilis occurred in

Table 2. Results of rank analysis on the abundance of each of 8 species on the 20 patch reefs for the 10 censuses. The rankings of a given species on reefs were used to calculate Kendall's coefficient of concordance across censuses

\begin{tabular}{lcccc|}
\hline Species & Concordance value & $\chi^{2}$ & df & probability \\
\hline Apogon doederlini & 0.565 & 107.3 & 19 & $\mathrm{p}<0.001$ \\
Apogon gracilis & - & - & - & - \\
Cheilodipterus quinquelineata & 0.545 & 103.65 & 19 & $\mathrm{p}<0.001$ \\
Acanthochromis polyacanthus & 0.606 & 115.2 & 19 & $\mathrm{p}<0.001$ \\
Chromis nitida & 0.610 & 115.8 & 19 & $\mathrm{p}<0.001$ \\
Dascyllus aruanus & 0.643 & 122 & 19 & $\mathrm{p}<0.001$ \\
Pomacentrus molluccensis & 0.608 & 115.6 & 19 & $\mathrm{p}<0.001$ \\
Gobiodon okinawe & - & - & - & - \\
\hline
\end{tabular}


only 5 of the 10 censuses, and in wildly varying numbers (e.g. 390 fish in Census 5, all on Reef 2, but 320 fish in Census 6, all on Reef 4). Gobiodon okinawe occurred in all censuses, and in consistent numbers, but on very few reefs (mean number per census, $45.4 \pm 3.2 \mathrm{SE}, 90 \%$ on Reef 18 and the remainder usually on Reef 13). Our conclusion was that with the possible exception of $A$. gracilis, the 8 species occurred consistently on certain of the 20 reefs, though numbers on any reef tended to vary markedly among censuses. Fig. 4 shows this graphically for Apogon doederleini and Pomacentrus molluscensis.

Species which showed such pronounced variation in abundance among reefs cannot have their distributions mimicked by a model which distributes individuals randomly from a pool common to all reefs. Deleting them from consideration has led to pseudoassemblages which were relatively more similar to the natural assemblages. We suggest that the pseudoassemblages generated by Model 2 usually contained more species

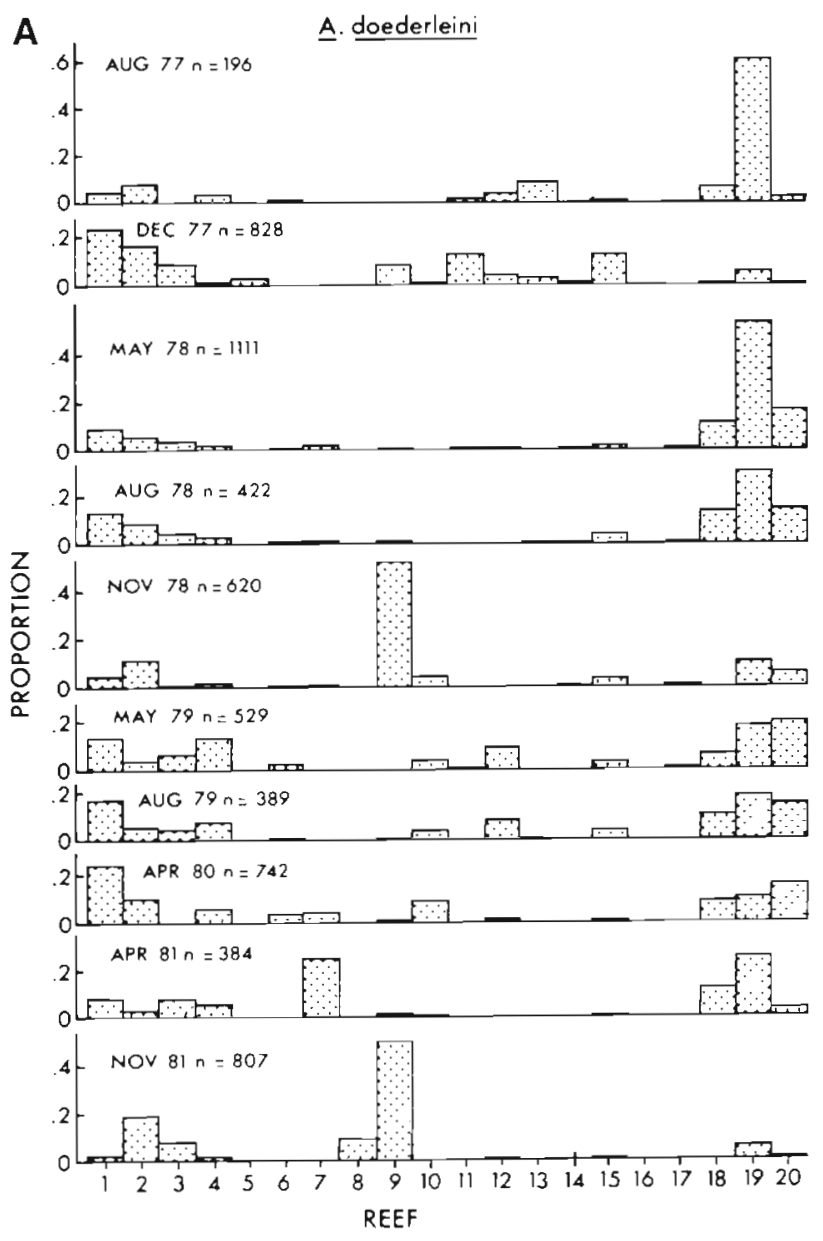

than the mimicked natural assemblages because some additional species, not deleted, also tend to show strong affinity for certain of the 20 reefs. Hence, the procedure of drawing these species from a common pool will tend to distribute them more evenly on reefs than they naturally occur. It is for this reason that the pseudoassemblages will tend to be more similar to one another than to the natural assemblages. It is clear that a small proportion of species, but including several common ones, are distributed significantly non-randomly among reefs. Their consistency of occurrence on certain reefs strongly suggests they respond to certain habitat features common to those reefs. An alternative possibility is that they recruit preferentially to existing groups of conspecifics.

Model 3, which deleted species which had never been recorded on a particular reef, gave a poor similarity between pseudo- and natural assemblages, but gave a good simulation of number of species. There are 2 possible reasons why reducing the size of the species

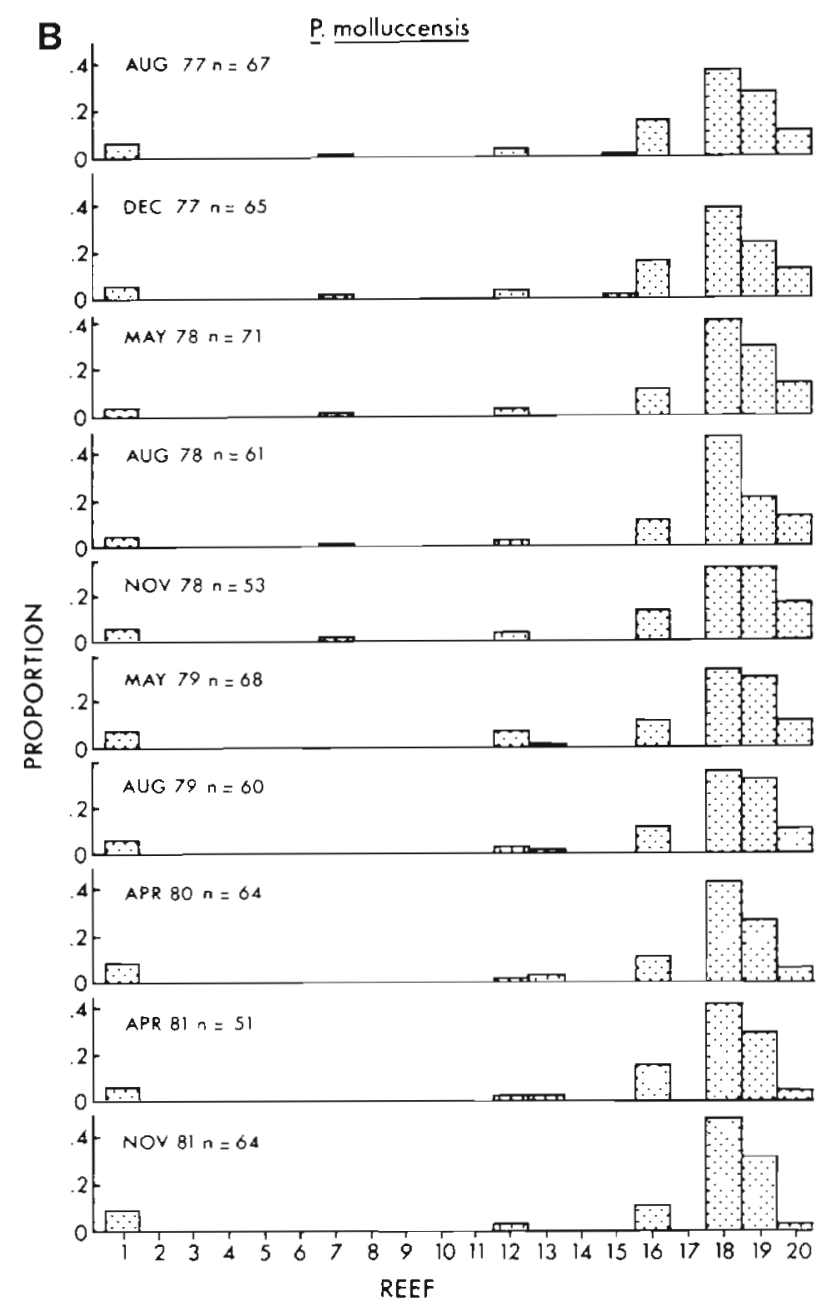

Fig. 4. Apogon doederleini and Pomacentrus molluccensis. Usage of reefs for each of the 10 censuses. Data are presented as the proportion of individuals present at each census that occurred on each of the 20 reefs. In both cases, certain reefs appear preferred and others avoided 
pool in this way improves the fit with number of species. The first, and the reason that Model 3 was developed, is that each reef might be attractive to only a subset of the total pool of 143 species. Certain species, as already stated, are habitat specialists, and will not occur on patch reefs lacking these habitats. The second possible reason for the improvement seen with Model 3 is that while each reef draws colonists from the great majority of the 143 species, the chance of settlement of many or all species may be heightened slightly if conspecifics are already present. The consequence of such a change in the probability of settlement would be to minimize the number of species present as single individuals on reefs. Model 3 does not simulate such a variable chance of recruitment directly. However, by eliminating from consideration all species which failed to occur on each particular reef, this model throws out, on each occasion, a substantial proportion of the species which occur only rarely in the system. The result is that pseudoassemblages generated are less likely to contain numbers of species represented by single individuals.

The results of simulations using Model 6 (Table 1) support the first of these possible reasons for Model 3's success. Model 6 eliminated the possibility of species being present on reefs as single individuals, and in this crude way provided for varying chance of recruitment of fish after 1 individual of that species arrived. The results show an improvement over Model 1, but remain poor compared to those of Model 3. Since the improvement seen in results from Model 3 is due to species not being equally capable of recruiting to all 20 reefs, we also conclude that habitat differences among reefs are the most likely cause of these differences in attractiveness to species.

Results obtained with Model 4 confirm that the effects examined in Models 2 and 3 are additive. Those obtained using Model 5 suggest that the habitat differences which appear to exist among the 20 reefs are not easily dealt with by considering the reefs as belonging to a northeast and a south group.

To summarize the discussion so far, there is a small group ( 8 or so) of common species which tend to be patchily distributed, though usually consistent in the reefs they avoid. The distribution of these species among reefs cannot be explained by postulating a random recruitment of individuals from a common pool. Whether they recruit in groups, or are strongly attracted by conspecifics, is not known. Nor are the cues known which appear to attract them to certain reefs. Although 3 of the 8 examined are microhabitat specialists requiring live branching coral, the reefs they occupied were not the only ones providing this microhabitat.

The distribution of the remainder of the 143 species can be reasonably closely approximated by a simple model of random recruitment of individuals from a common pool to the reefs. Such an approach (Model 2) yields pseudoassemblages just as similar to mimicked natural assemblages as are successive real assemblages on single reefs (Sale \& Douglas 1984). However, these pseudoassemblages tend to contain more species than the natural ones they mimic - an indication, as confirmed by Model 3, that even among these less common species there are ones which consistently avoid certain reefs. Recruitment of individuals of a species is not equally likely to all reefs.

The evidence that some species avoid certain reefs may appear to be at variance with the results of Sale \& Douglas (1984). Although these workers also found that the distribution of a few species was associated with aspects of reef structure other than size, their list of such species is not identical to ours. In particular, 3 very abundant, strongly social species (Apogon doederleini, Cheilodipterus quinquelineata, and Acanthochromis polyacanthus) identified by us as not conforming to a model of random placement were listed by Sale \& Douglas (1984) as having abundances on reefs correlated only with area or volume of the reef. This discrepancy arises because (1) their analyses considered mean abundances on reefs over several censuses, and these change markedly from one census to another (e.g. Fig. 4 A), and (2) they tested for significant association of particular species with specific reef attributes while we have examined goodness-of-fit of our model only with respect to number of species or fish present on reefs. Distributions of these very abundant species strongly influence total number of fish present on reefs and their distributions are not totally accounted for by variation in reef size.

In contrast Sale et al. (1984) and Eckert (in press) have shown, for several species included here, that microhabitats chosen at settlement have characteristics which distinguish them from randomly chosen sites on the reefs. This implies that settlement is not a random process. This contradiction with our results, which indicate that most species act according to a model of random placement, can be reconciled by recognizing the difference in spatial scale of the studies. We have worked at the level of whole patch reefs, each of which provides a multitude of small sites to be chosen by settling juveniles.

All of the models tested (except Model 6) are noninteractive, in the sense that recruitment of individuals to assemblages is not affected by the set of fish already present. The relative success of the models must cause us to question whether intra- and interspecific interactions play a significant role in determining the structure of real assemblages. In contrast to the considerable evidence available on habitat responses of settl- 
ing fish, there exist at present as evidence of responses among fish only Sweatman's (1983) demonstration of positive responses to conspecifics by 2 species of Dascyllus, the negative interspecific responses during the establishment of assemblages documented by Shulman et al. (1983) and Ebersole (1985), and the analyses by Sale \& Dybdahl $(1975,1978)$ and by Talbot et al. (1978) of associations among species occupying patch reef habitats. In the present study, some of the species excluded by Model 2 probably respond positively to conspecifics when settling. More effort to elucidate such interactions is needed.

In conclusion, by modelling the distribution of species across patch reefs we have shown that while a process of random colonization can account for much of the structure in the distribution of species it is not a complete explanation for the observed distribution of all species. By modifying the original model we have identified 2 groups of species. The first group is small, but consists of some numerically abundant species. Their distributions across patch reefs cannot be explained by a model of random placement, and there are clearly other factors influencing their distributions. More research is needed in this area. For the remaining group of species, while it is possible that some subtle but real microhabitat preferences are occurring, a model of random placement still remains a reasonable explanation for their distributions.

Acknowledgements. This work was supported by a grant to P. F. Sale from the Australian Research Grants Committee. We thank Bill Douglas and Rand Dybdahl for assistance in the field program, and the One Tree Group for useful discussion. This is a contribution from the University of Sydney's One Tree Island Field Station.

\section{LITERATURE CITED}

Anderson, G. R. V., Ehrlich, A. H., Ehrlich, P. R., Rougharden, J. D., Russell, B. C., Talbot, F. H. (1981). The community structure of coral reef fishes. Am. Nat. 117:476-495

Bohnsack, J. A., Talbot, F. H. (1980). Species packing by reef fishes on Australian and Caribbean reefs: an experimental approach. Bull. mar. Sci. 30: 710-723

Brock, R. E., Lewis, C., Wass, W C. (1979). Stability and structure of a fish community on a coral patch reef in Hawaii. Mar. Biol. 54: 281-292

Cody, M. L., Diamond, J. M. (ed.) (1975). Ecology and evolution of communities. Belknap Press (Harvard Univ. Press), Cambridge, Massachussetts

Doherty, P. J., Sale, P. F. (1985). Predation on juvenile coral reef fishes: an exclusion experiment. Coral Reefs (in press)

Ebersole, J. P. (1985). Niche separation of two damselfish species by aggression and differential microhabitat utilization. Ecology 66: 14-20

Eckert, G. J. (in press). Settlement of coral reef fishes to different natural substrata and depths. Proc. 5th. int. Coral Reef Congress, Tahiti, May 1985

Gladfelter, W B., Ogden, J. C., Gladfelter, E. H. (1980).
Similarity and diversity among coral reef fish communities: a comparison between tropical western Atlantic (Virgin Islands) and tropical central Pacific (Marshall Islands) patch reefs. Ecology 61: 1156-1168

McGuinnes, K. A. (1984). Species-area relations of communities on intertidal boulders: testing the null hypothesis. J. Biogeog. 11: 439-456

Ogden, J. C., Ebersole, J. P. (1981). Scale and community structure of coral reef fishes: a long-term study of a large artificial reef. Mar. Ecol. Prog. Ser. 4: 97-104

Robertson, D. R. (1973). Field observations on the reproductive behaviour of a pomacentrid fish, Acanthochromis polyacanthus. Z. Tierpsychol, 32: 319-324

Sale, P. F. (1977). Maintenance of high diversity in coral reef fish communities. Am. Nat. 111: 337-359

Sale, P. F. (1979). Recruitment, loss and coexistence in a guild of coral reef fishes. Oceologia (Berl.) 42: 159-179

Sale, P. F. (1980). The ecology of fishes on coral reefs. Oceanogr. mar Biol. A. Rev. 18: 367-421

Sale, P. F., Douglas, W. A. (1981). Precision and accuracy of visual census techniques for fish assemblages on coral patch reefs. Environ. Biol. Fish. 6: 333-339

Sale, P. F., Douglas, W. A. (1984). Temporal variability in the community structure of fish on coral patch reefs and the relation of community structure to reef structure. Ecology 65: 409-422

Sale, P. F., Douglas, W. A., Doherty, P. J. (1984). Choice of microhabitats by coral reef fishes at settlement. Coral Reefs 3: 91-99

Sale, P. F., Dybdahl, R. (1975). Determinants of community structure for coral reef fishes in an experimental habitat. Ecology 56: 1343-1355

Sale, P. F., Dybdahl, R. (1978). Determinants of community structure for coral reef fishes in isolated coral heads at lagoonal and reef slope sites. Oecologia (Berl.) 34: 57-74

Shulman, M. J., Ogden, J. C., Ebersole, J. P., McFarland, W. N., Miller, S. L., Wolf, N. G. (1983). Priority effects in the recruitment of juvenile coral reef fishes. Ecology 64 1508-1513

Simberloff, D. S. (1978). Use of rarefaction and related methods in ecology. Biological data in pollution assessment: quantitative and statistical analyses. In: Dickson, $K$. L., Cairns, J. Jr., Livingstone, R. J. (ed.) Am. Soc. for Testing and Materials, Philadelphia p. 150-165

Smith, C. L., Tyler, J. C. (1972). Space resource sharing in a coral reef fish community. Natural History Museum of Los Angeles County Science Bulletin 14: 125-170

Smith, C. L., Tyler, J. C. (1975). Succession and stability in fish communities on dome-shaped patch reefs in the West Indies. American Museum Novitates 2572: 1-18

Strong, D. R., Simberloff, D. S., Abele, L. G., Thistle, A. (1984). Ecological communities: conceptual issues and the evidence. Princeton Univ. Press, Princeton, New Jersey

Sweatman, H. P. A. (1983). Influence of conspecifics on choice of settlement sites by larvae of two pomacentrid fishes (Dascyllus aruanus and D. recticulatus). Mar. Biol. 75: 225-230

Talbot, F. H., Russell, B. C., Anderson, G. R. V (1978). Coral reef fish communities: unstable high-diversity systems? Ecol. Monogr. 49: 425-440

Thresher, R. E. (1983). Habitat effects on reproductive success in the coral reef fish Acanthochromis polyacanthus (Pomacentridae). Ecology 64: 1184-1199

Thresher, R. E. (1984). Reproduction in reef fishes. T F. H Publications Inc., Neptune City, New Jersey 